\title{
Geometri Jalan Rel Kamal-Pelabuhan Tanjung Bulupandan di Madura
}

\author{
Muhammad Zainal Muttaqin, Wahju Herijanto, dan Budi Rahardjo \\ Departemen Teknik Sipil, Institut Teknologi Sepuluh Nopember (ITS) \\ Corresponding Author: rahardjo@ce.its.ac.id
}

\begin{tabular}{|c|c|}
\hline ARTIKEL INFO & ABSTRAK \\
\hline $\begin{array}{l}\text { Kata Kunci } \\
\text { Geometri Jalan Rel, Konstruksi Jalan } \\
\text { Rel, Rencana Anggaran Biaya, Kamal- } \\
\text { Pelabuhan Tanjung Bulupandan }\end{array}$ & $\begin{array}{l}\text { Di dalam Rencana Tata Ruang Wilayah Bangkalan tahun 2009-2019 } \\
\text { terdapat rencana pengembangan strategis jalur kereta api terutama } \\
\text { untuk melayani angkutan massal regional maupun nasional baik } \\
\text { penumpang maupun barang bagi wilayah industri terutama pelabuhan } \\
\text { serta melayani terminal penumpang laut. Sedangkan Kabupaten } \\
\text { Bangkalan memiliki rencana pengembangan prasarana transportasi laut } \\
\text { yaitu proyek pembangunan Pelabuhan Peti Kemas Tanjung } \\
\text { Bulupandan di Kecamatan Klampis sebagai pelabuhan peti kemas } \\
\text { internasional, serta pengembangan zona industri di kawasan pelabuhan } \\
\text { peti kemas. Adapun tujuan yang akan dicapai dalam pembangunan } \\
\text { jaringan jalan rel Kabupaten Bangkalan antara lain dari aspek } \\
\text { transportasi ialah berkurangnya konstruksi jalan raya dan pemakaian } \\
\text { energi dalam jumlah yang besar dengan adanya perpindahan angkutan } \\
\text { massal dari jalan raya ke jalan rel. Metode yang digunakan dalam } \\
\text { menyelesaikan permasalahan adalah mengumpulkan data sekunder, } \\
\text { menentukan rute terbaik beberapa alternatif rute menggunakan multi } \\
\text { criteria analysis, membuat Gambar geometrik dari rute yang terpilih } \\
\text { dan membuat rencana anggaran biaya (RAB). Hasil dari studi ini } \\
\text { adalah rencana trase Kamal-Pelabuhan Tanjung Bulupandan. Jalur } \\
\text { kereta api didesain menggunakan jenis rel R54 dengan lebar sepur } \\
1067 \text { mm, kecepatan maksimum } 120 \text { km/jam, jenis penambat pandrol } \\
\text { elastik tunggal, Panjang trase yang dirancang sepanjang } 37,1 \text { km } \\
\text { menggunakan bantalan beton dengan jarak } 60 \text { cm. Dan rencana } \\
\text { anggaran biaya yang dibutuhkan sebesar Rp. } 785.448 .669 .000\end{array}$ \\
\hline
\end{tabular}

\section{PENDAHULUAN}

Kereta api adalah sarana perkeretaapian dengan tenaga gerak, baik berjalan sendiri maupun dirangkaikan dengan sarana perkeretaapian lainnya, yang akan ataupun sedang bergerak di jalan rel terkait dengan perjalanan kereta api [1]. Di negara Indonesia kereta api bukan menjadi pilihan utama bagi masyarakat. Pmoda transportasi jalan rel memiliki harga yang relatif murah, serta bisa digunakan untuk mengangkut orang dan barang dalam jumlah besar. Jaringan rel di Indonesia sendiri masih tergolong sedikit dan tidak merata. Pada tahun 2009 panjang jalan kereta api yang beroperasi hanya sebesar $4,684 \mathrm{~km}$, turun $31,2 \%$ dibandingkan panjang jalan kereta api pada tahun 1939 [2]. Sedangkan di Pulau Madura, saat ini jalur kereta api yang ada sudah tidak beroperasi. Jalur kereta api di Madura pertama kali dibuka oleh Pemerintah Hindia Belanda pada tahun 1898. Tetapi pada masa pendudukan jepang, banyak rel yang dibongkar oleh Jepang untuk dijadikan senjata dan pada masa kemerdekaan jalur kereta yang tersisa hanya jalur Pamekasan sampai Kamal. Namun seiring dengan perkembangan jaman, moda transportasi kereta api di Madura mulai ditinggalkan dan beralih ke angkutan lain.
Sehingga pada tahun 1987, jalur kereta api di Madura resmi ditutup. Dan kondisi jalur kereta api yang ada di Madura pada umumnya dalam kondisi rusak.

Sesuai arahan pengembangan perkeretaapian nasional dalam Rencana Induk Perkeretaapian tahun 2011 diharapkan sarana kereta api terintegrasi dengan moda lain, terjangkau oleh seluruh lapisan masyarakat, serta tersebar di pulau-pulau besar, salah satunya yaitu Pulau Madura. Transportasi di Madura saat ini mengandalkan jaringan jalan raya. Hanya terdapat 1 jalur nasional yang menghubungkan antara kecamatan Kamal, Kabupaten Bangkalan sampai dengan kecamatan Kalianget, Kabupaten Sumenep. Pada tahun 2016 tercatat 7,5 juta kendaraan masuk maupun keluar melewati Jembatan Suramadu. Berdasarkan Rencana Tata Ruang Wilayah Kabupaten Bangkalan tahun 2009-2029 terdapat rencana pengembangan strategis jalur kereta api terutama untuk melayani angkutan massal regional maupun nasional baik penumpang maupun barang bagi wilayah industry terutama pelabuhan serta melayani terminal penumpang laut [3]. Rencana jalur yang dibangun merupakan revitalisasirel kereta api Kamal-Sampang-PamekasanSumenep. Untuk pengembangan jalur kereta api Kamal- 
Socah-Bangkalan terdapat didalam Rencana Induk

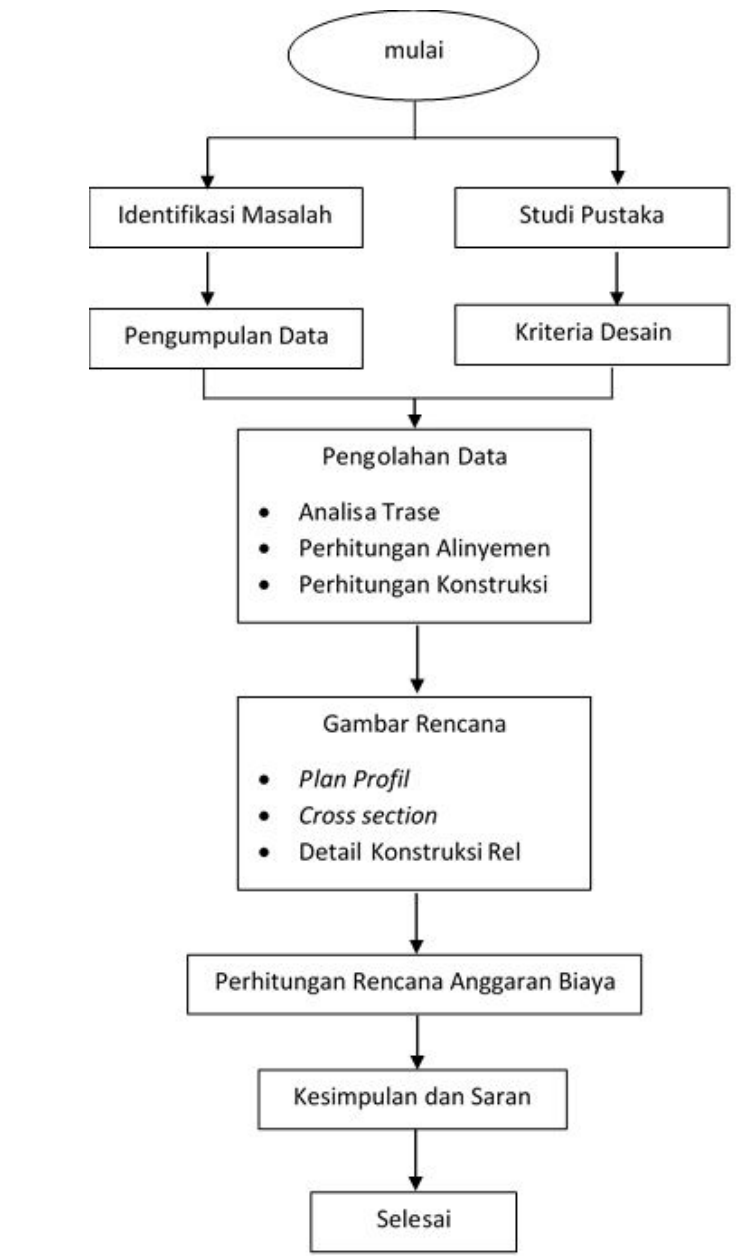

Gambar 1. Diagram Alir Metodologi Pengerjaan Studi.

Perkeretaapian Nasional.

Di sisi lain Kabupaten Bangkalan juga memiliki rencana pengembangan prasarana transportasi laut yaitu proyek pembangunan Pelabuhan Peti Kemas Tanjung Bulupandan di Kecamatan Klampis sebagai pelabuhan peti kemas internasional, serta pengembangan zona industri di kawasan pelabuhan peti kemas. Kemudian pengembangan Kota Metropolitan Bangkalan yang terdiri dari Kota Bangkalan dan Perkotaan sekitar Kawasan Kaki Jembatan Suramadu dan kota satelit (Perkotaan Socah dan Perkotaan Klampis) yang didukung oleh sistem angkutan massal perkotaan. Namun pembangunan infrastruktur Kabupaten Bangkalan pendukung yang direncanakan hanya sebatas pembangunan jalan kolektor primer yang menghubungkan antar daerah, salah satunya Padahal untuk distribusi barang khususnya untuk mendukung Pelabuhan Peti Kemas Tanjung Bulupandan membutuhkan distribusi barang yang banyak apabila menggunakan moda transportasi berbasis jalan seperti truk maupun trailer. Kondisi ini tidak didukung dengan kondisi jalan yang berdasarkan tahun 2016 terdapat kondisi jalan rusak berat sepanjang $188.683 \mathrm{~km}$, sehingga dapat meningkatkan resiko menambah beban jalan Kabupaten Bangkalan.

Adapun tujuan yang akan dicapai dalam pembangunan jaringan jalan rel Kabupaten Bangkalan antara lain dari aspek ekonomi mendukung pembangunan ekonomi yang hanya mengalami pertumbuhan $0,66 \%$ pada tahun 2016 sehingga diharapkan dapat meningkatkan taraf hidup masyarakat. Dan dari aspek transportasi ialah berkurangnya konstruksi jalan raya dan pemakaian energi dalam jumlah yang besar dengan adanya perpindahan angkutan barang dari jalan raya ke jalan rel.

\section{METODE PENELITIAN}

Metodologi yang dilakukan pada tahap perencanaan studi ini pertama-tama melakukan perumusan masalah yang ada seperti perencanaan trase jalan rel yang sesuai topografi, konstruksi jalan rel, volume galian dan timbunan. Untuk diagram dapat dilihat pada Gambar 1.

\section{ANALISIS TRASE DAN PERENCANAAN}

\section{A. Analisis Trase}

Dalam Analisis alternatif trase Kamal-Pelabuhan Tanjung Bulupandan terdapat tiga alternatif trase yang masing-masing memiliki kelebihan dan kekurangan.

a) Alternatif trase 1 Pada alternatif 1 pertimbangan yang yang adalah Panjang trase $35,7 \mathrm{~km}$, melewati Kecamatan Socah, terdapat 7 perlintasan sebidang . untuk lokasi trase dapat dilihat pada Gambar 2.

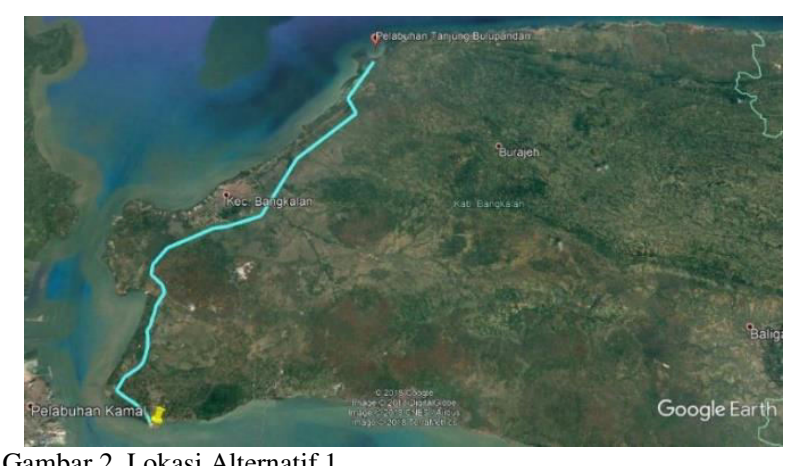

Gambar 2. Lokasi Alternatif 1.

b) Alternatif trase 2

Pada alternatif 1 pertimbangan yang yang adalah Panjang trase $32,9 \mathrm{~km}$, melewati bekas jalur kereta lama, berdampingan dengan jalan nasional rute 21 , untuk lokasi trase dapat dilihat pada Gambar 3.

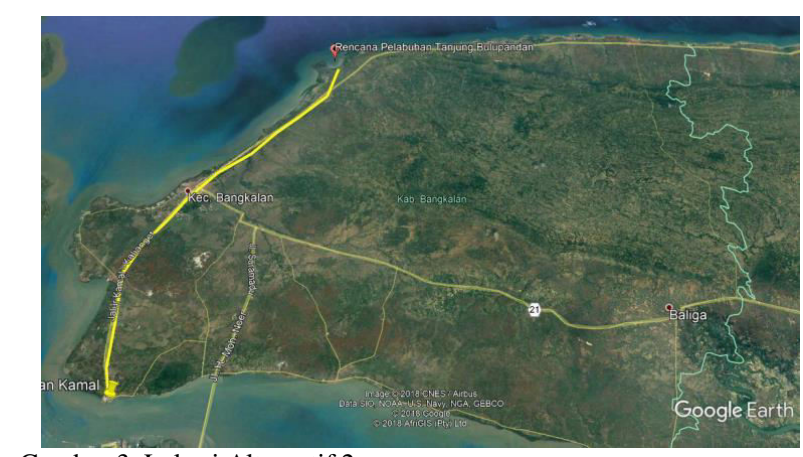

Gambar 3. Lokasi Alternatif 2.

c) Alternatif trase 3

Pada alternatif 3 pertimbangan yang yang adalah Panjang trase $37,1 \mathrm{~km}, 800$ meter dari pintu masuk universitas 
Trunojoyo madura, terdapat 6 titik perlintasan sebidang. untuk lokasi trase dapat dilihat pada Gambar 4

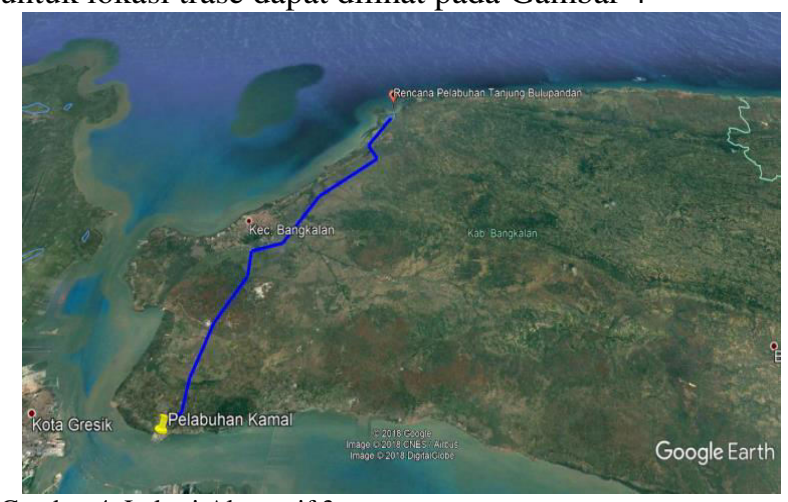

Gambar 4. Lokasi Alternatif 3.

\section{B. Pemilihan Trase}

Analisis trase terpilih dilakukan dengan metode multi criteria analysis yaitu dengan menggunakan matriks pairwise comparison dengan kriteria yang sudah ditentukan dengan poin rentang 1-3 yang akhirnya memunculkan nilai dari masing-masing trase dan nilai terbesar diambil sebagai alternatif trase terpilih. Untuk nilai masing-masing kriteria dapat dilihat pada Tabel 1.

Tabel 1. Nilai Multi Criteria Analysis Masing-Masing Kriteria

\begin{tabular}{|c|c|c|c|}
\hline \multirow{2}{*}{ Kriteria } & \multicolumn{3}{|c|}{ Poin } \\
\hline & Low & Medium & High \\
\hline Panjang Lintasan & 3 & 2 & 1 \\
\hline Konstruksi Jembatan & 3 & 2 & 1 \\
\hline Perlintasan Sebidang & 3 & 2 & 1 \\
\hline Pembebasan Pemukiman & 3 & 2 & 1 \\
\hline Pembebasan Sawah & 3 & 2 & 1 \\
\hline Pembebasan Makam & 3 & 2 & 1 \\
\hline Daerah Pemukiman & 1 & 2 & 3 \\
\hline Daerah Pasar & 1 & 2 & 3 \\
\hline Daerah Kampus & 1 & 2 & 3 \\
\hline
\end{tabular}

Untuk bobot dihitung menghitung menggunakan matriks pairwise yang dapat dilihat pada buku studi ini. Untuk hasil bobot yang digunakan dapat dilihat pada Tabel 2.

Tabel 2. Bobot Multi Kriteria Analysis

\begin{tabular}{lc}
\hline \multicolumn{1}{c}{ Kriteria } & Bobot \\
\hline Pembebasan Pemukiman & 19,0 \\
Perlintasan Sebidang & 16,5 \\
Pembebasan Makam & 14,2 \\
Konstruksi Jembatan & 12,1 \\
Daerah Pemukiman & 10,3 \\
Panjang Lintasan & 8,8 \\
Daerah Pasar & 7,4 \\
Daerah Kampus & 6,3 \\
Pembebasan Sawah & 5,5 \\
\hline
\end{tabular}

Untuk hasil akhir perhitungan multi criteria analysis pada alternatif 1 dapat dilihat pada Tabel 3

Tabel 3. Multi Kriteria Analysis Alternatif 1

\begin{tabular}{lccc}
\hline \multicolumn{1}{c}{ Kriteria } & Bobot & Nilai & Bobot x Nilai \\
\hline Pembebasan Pemukiman & 19,0 & 3 & 57,0 \\
Perlintasan Sebidang & 16,5 & 2 & 33,0 \\
Pembebasan Makam & 14,2 & 3 & 42,6 \\
Konstruksi Jembatan & 12,1 & 1 & 12,1 \\
Daerah Pemukiman & 10,3 & 1 & 10,3 \\
Panjang Lintasan & 8,8 & 2 & 17,6 \\
Daerah Pasar & 7,4 & 2 & 14,8 \\
Daerah Kampus & 6,3 & 1 & 6,3
\end{tabular}

Pembebasan Sawah $\begin{array}{cc}5,5 & 1 \\ & \text { Total }\end{array}$ 5,5 199,2

Untuk hasil akhir perhitungan multi criteria analysis pada alternatif 2 dapat dilihat pada Tabel 4.

Tabel 4. Multi Kriteria Analysis Alternatif 2

\begin{tabular}{lccc}
\hline \multicolumn{1}{c}{ Kriteria } & Bobot & Nilai & Bobot x Nilai \\
\hline Pembebasan Pemukiman & 19,0 & 1 & 19,0 \\
Perl'intasan Sebidang & 16,5 & 1 & 16,5 \\
Pembebasan Makam & 14,2 & 2 & 28,4 \\
Konstruksi Jembatan & 12,1 & 2 & 24,2 \\
Daerah Pemukiman & 10,3 & 3 & 30,9 \\
Panjang Lintasan & 8,8 & 3 & 26,4 \\
Daerah Pasar & 7,4 & 3 & 22,2 \\
Daerah Kampus & 6,3 & 2 & 12,6 \\
Pembebasan Sawah & 5,5 & 3 & 16,5 \\
& & Total & 196,7 \\
\hline
\end{tabular}

Untuk hasil akhir perhitungan multi criteria analysis pada alternatif 3 dapat dilihat pada Tabel 5.

Tabel 5. Multi Kriteria Analysis Alternatif 3

\begin{tabular}{lccc}
\hline \multicolumn{1}{c}{ Kriteria } & Bobot & Nilai & Bobot x Nilai \\
\hline Pembebasan Pemukiman & 19,0 & 2 & 38,0 \\
Perl'intasan Sebidang & 16,5 & 3 & 49,5 \\
Pembebasan Makam & 14,2 & 1 & 14,2 \\
Konstruksi Jembatan & 12,1 & 3 & 36,3 \\
Daerah Pemukiman & 10,3 & 2 & 20,6 \\
Panjang Lintasan & 8,8 & 1 & 8,8 \\
Daerah Pasar & 7,4 & 1 & 7,4 \\
Daerah Kampus & 6,3 & 3 & 18,9 \\
Pembebasan Sawah & 5,5 & 2 & 11,0 \\
& & Total & 204,7 \\
\hline
\end{tabular}

Karena pada alternatif 3 didapat poin paling besar, dipilih alternatif trase 3 sebagai perencanaan

\section{Alinyemen Horizontal}

Sesuai desain trase terpilih pada bab sebelumnya direncanakan alinyemen dengan kecepatan maksimum $120 \mathrm{~km} / \mathrm{jam}$, lengkung minimum $780 \mathrm{~m}$, geometri lengkung menggunakan lengkung peralihan, peninggian maksimum $110 \mathrm{~mm}$. Hasil perhitungan didapat seperti pada Gambar 5 dan Tabel 6

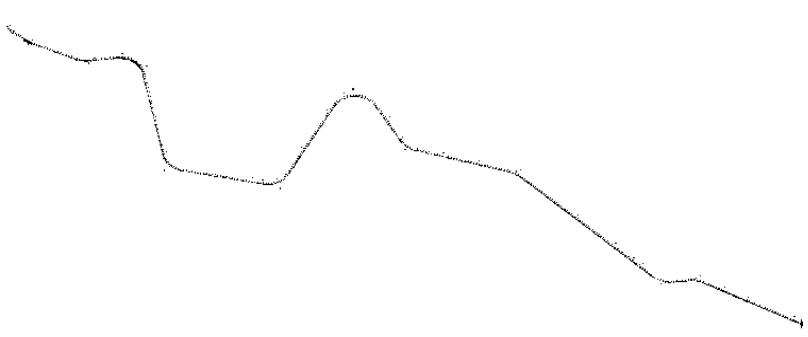

Gambar 5. Alinyemen Horizontal Jalur Kereta Kamal-Pelabuhan Tanjung Bulupandan.

Tabel 6. Perhitungan Alinyemen Horizontal

\begin{tabular}{lcclcc}
\hline \multicolumn{1}{c}{ Titik } & $\begin{array}{c}\text { Koordinat } \\
\mathrm{X}\end{array}$ & $\begin{array}{c}\text { Koordinat } \\
\text { Y }\end{array}$ & $\begin{array}{c}\Delta \text { (sudut } \\
\text { tikungan) }\end{array}$ & $\begin{array}{c}\mathrm{V} \\
\text { rencana }\end{array}$ & $\begin{array}{c}\mathrm{R} \\
\text { rencana }\end{array}$ \\
\hline Kamal & 585714,009 & 9235317,602 & & & \\
PI 1 & 586364,131 & 9236061,518 & 17,225 & 120 & 780 \\
PI 2 & 587200,998 & 9237947,684 & 32,377 & 120 & 780 \\
PI 3 & 586917,793 & 9239853,778 & 87,175 & 120 & 784 \\
PI 4 & 591789,998 & 9240825,188 & 66,994 & 120 & 780 \\
PI 5 & 592599,120 & 9244721,786 & 73,428 & 120 & 780 \\
PI 6 & 587850,725 & 9247278,826 & 121,890 & 120 & 784 \\
PI 7 & 590926,572 & 9249040,883 & 44,024 & 120 & 780 \\
PI 8 & 592024,501 & 9252827,623 & 27,293 & 120 & 784
\end{tabular}




\begin{tabular}{llllll} 
PI 9 & 596764,062 & 9257828,643 & 49,718 & 120 & 780 \\
PI 10 & 596630,068 & 9259051,048 & 34,256 & 120 & 784 \\
T. Bulu & 598481,526 & 9262533,002 & & & \\
\hline
\end{tabular}

D. Alinyemen Vertikal

Sesuai desain trase terpilih pada bab sebelumnya direncanakan alinyemen dengan kecepatan maksimum $120 \mathrm{~km} / \mathrm{jam}$, lengkung $8000 \mathrm{~m}$, gradien rencana maksimum 1\%o, Hasil perhitungan dapat dilihat pada Tabel 7.

Tabel 7. Perhitungan Alinyemen Vertikal

\begin{tabular}{rcccccc}
\hline PPV & STA & STA & $\begin{array}{c}\text { El. } \\
\text { PPV }\end{array}$ & g1 $(\%)$ & $\mathrm{g} 2(\%)$ & $\begin{array}{c}\mathrm{R} \\
(\mathrm{m})\end{array}$ \\
\hline PPV 1 & $0+600$ & $1+900$ & 11,0 & $0,00 \%$ & $1,00 \%$ & 8000 \\
PPV 2 & $1+900$ & $5+600$ & 24,0 & $1,00 \%$ & $0,00 \%$ & 8000 \\
PPV 3 & $5+600$ & $8+500$ & 25,0 & $0,00 \%$ & $0,90 \%$ & 8000 \\
PPV 4 & $8+500$ & $9+000$ & 45,0 & $0,90 \%$ & $0,00 \%$ & 8000 \\
PPV 5 & $9+000$ & $10+400$ & 45,0 & $0,00 \%$ & $-0,89 \%$ & 8000 \\
PPV 6 & $10+400$ & $12+900$ & 12,5 & $-0,89 \%$ & $-1,00 \%$ & 8000 \\
PPV 7 & $12+900$ & $14+400$ & 5,0 & $-1,00 \%$ & $-2,02 \%$ & 8000 \\
PPV 8 & $14+400$ & $19+100$ & 5,0 & $-2,02 \%$ & $0,00 \%$ & 8000 \\
PPV 9 & $19+100$ & $33+600$ & 5,0 & $0,00 \%$ & $0,75 \%$ & 8000 \\
PV 10 & $33+600$ & $34+000$ & 5,0 & $0,75 \%$ & $0,00 \%$ & 8000 \\
\hline
\end{tabular}

\section{E. Tipikal Struktur Jalan Rel}

Sesuai dengan kelas jalan rel 1 pada Peraturan Menteri No. 60 tahun 2012 struktur jalan rel digambarkan pada Gambar 6.

1. Digunakan R54

2. Daya Angkut Lalu Lintas $>20$ Juta/ton

3. Beban Gandar 18 Ton

4. Jarak antar bantalan $60 \mathrm{~cm}$

5. Tebal balas dibawah bantalan $30 \mathrm{~cm}$

6. Tebal sub balas $50 \mathrm{~cm}$

7. Tipe Penambat pandrol

8. Sambungan Las termit

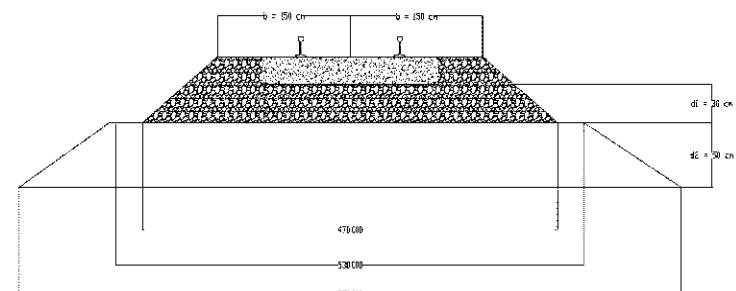

Gambar 6. Alinyemen Vertikal Jalur Kereta Kamal-Pelabuhan Tanjung Bulupandan.

\section{F. Perencanaan Peron}

Peron adalah bangunan yang terletak di samping jalur kereta api yang berfungsi untuk naik turun penumpang. Perencanaan peron disesuaikan dengan penampang melintang moda kereta api yang melintas.

Dari data yang didapat dirancang peron dengan dimensi sebagai berikut:

\section{Panjang peron $\quad: 80 \mathrm{~m}$}

Lebar peron dihitung berdasarkan jumlah penumpang dengan menggunakan rumus:

$$
b=\frac{0,64 m 2 / \text { orang } x V \times L F}{I}
$$

Dimana $: \mathrm{b}=$ Lebar peron $\mathrm{m}$

$\mathrm{V}=$ Jumlah maksimum penumpang kereta LF $=$ Load factor $80 \%$

$$
\begin{aligned}
\mathrm{I} & =\text { Panjang peron } \\
\mathrm{B} & =(0,64 \times 624 \times 80 \%) / 80 \\
& =4 \mathrm{~m}
\end{aligned}
$$

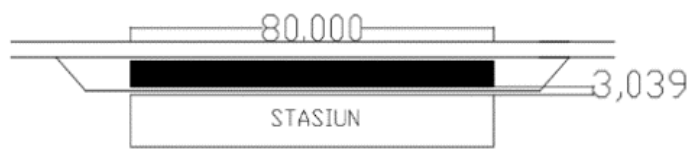

Gambar 7. Dimensi Peron dalam Meter.

\section{G. Wesel dan Emplasemen}

Perencanaan wesel dan emplasemen disesuaikan dengan kebutuhan stasiun

a) Stasiun Kamal

Denah Stasiun Kamal seperti pada Gambar 8

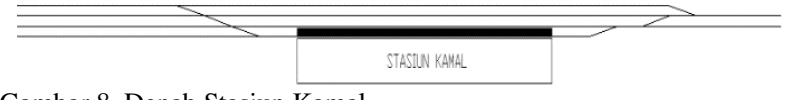

Gambar 8. Denah Stasiun Kamal.

b) Halte Telang

Denah Stasiun Kamal seperti pada Gambar 9

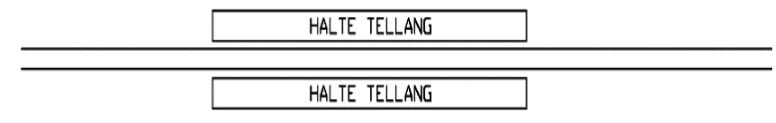

Gambar 9. Denah Halte Talang.

c) Stasiun Socah

Denah Stasiun Kamal seperti pada Gambar 10

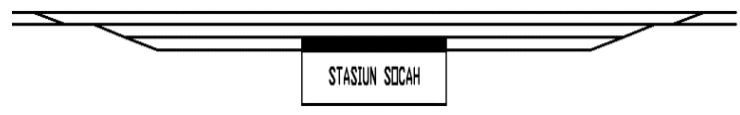

Gambar 10. Denah Stasiun Socah.

d) Stasiun Bangkalan

Denah Stasiun Kamal seperti pada Gambar 11

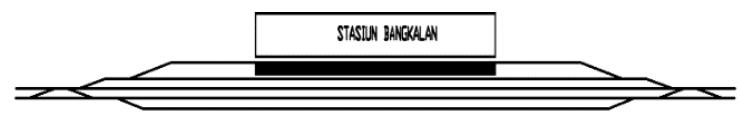

Gambar 11. Denah Stasiun Bangkalan.

e) Stasiun Tanjung Bulupandan

Denah Stasiun Kamal seperti pada Gambar 12

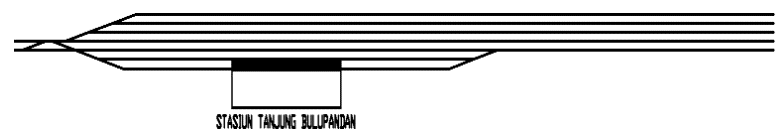

Gambar 12. Denah Stasiun Tanjung Bulupandan.

\section{E. Rekapitulasi Rencana Anggaran Biaya}

Rekapitulasi dari volume dan daftar harga satuan harga dari pekerjaan dijadikan rencana anggaran biaya:

Pekerjaan Persiapan

Rp. 17.681.963.245,27

Pekerjaan Tubuh Jalan

Rp. 696.362.280.480,81

dan Track

$\begin{array}{ll}\text { Total } & \text { Rp. } 714.044 .243 .726,08 \\ \text { PPn }+10 \% & \text { Rp. } 71.404 .424 .372,61 \\ \text { Total }+ \text { PPn } & \text { Rp. 785.448.669.000,00 }\end{array}$


Total sejumlah Tujuh Ratus Delapan Puluh Lima Miliar Empat Ratus Empat Puluh Delapan Juta Enam Ratus Enam Puluh Sembilan Ribu Rupiah

\section{KESIMPULAN}

Dari hasil perancangan jalan rel jalur Kamal-Pelabuhan Tanjung Bulupandan sebagaimana yang telah disebutkan diatas didapatkan rincian sebagai berikut

1. Trase terpilih adalah alternative trase jalan rel 3

2. Perencanaan lengkung horizontal menggunakan kecepatan rencana $120 \mathrm{~km} / \mathrm{jam}$, jari-jari minimum 780 m didapatkan 10 tikungan; sedangkan lengkung vertikal direncanakan dengan kelandaian $0 \%$ - 4\%o, radius $8000 \mathrm{~m}$ didapatkan 10 lengkung

3. Struktur Jalan rel yang digunakan didapatkan sebagai berikut:
a. Tipe rel R54
b. Lebar sepur $1067 \mathrm{~mm}$

c. Jarak bantalan beton $60 \mathrm{~cm}$

d. Tebal balas dibawah bantalan $30 \mathrm{~cm}$

e. Tipe penambat pandrol

f. Sambungan Las termit

g. Tebal balas atas $30 \mathrm{~cm}$

h. Tebal balas bawah $50 \mathrm{~cm}$

i. Tipe wesel yang digunakan $\mathrm{W} 14$

j. Peron tinggi dengan panjang $100 \mathrm{~m}$ dan lebar $4 \mathrm{~m}$

4. Biaya yang dibutuhkan Rp. 785.448.669.000,00

\section{DAFTAR PUSTAKA}

[1] Menteri Perhubungan Republik Indonesia, "Peraturan Menteri Perhubungan Nomor : PM.60 TAHUN 2012,” 2012.

[2] Kementrian Perhubungan and Ditjen Perkeretaapian, "Rencana Induk Perkeretaapian Nasional,” Jakarta, 2011.

[3] P. Daerah and K. Bangkalan, "PEMERINTAH Kabupaten Bangkalan Nomor 10 Tahun 2009 Tentang Rencana Tata Ruang Wilayah Kabupaten Bangkalan Tahun 2009 - 2029," 2009. 